Editorial

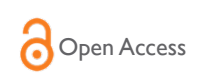

D) CrossMark

\title{
White treasure in the desert
}

\section{Editorial}

Many questions have been raised during the last three decades about the white treasure, however most of the available information in the literature at that time was not abundant. This is because most of the produced white treasure was in the desert areas which is far from urban and commercial markets. Moreover, its production is consumed locally by families and their animals. In fact, this type of treasure has an important role in human nutrition for those living in the hot regions and arid countries. White treasure is used worldwide for a long time as a treatment for many diseases include dropsy, jaundice, tuberculosis, asthma and leishmaniasis. Lacking scientific data has encouraged many researchers to study the production, population, composition, nutritional value, and health claims of camel milk (white treasure). Currently, the available information in the literature have answered many raised questions. Although the gross chemical composition (proteins, fat, lactose, ash) of camel milk are convergent to other mammalian milks; few differences in some sub-constituents were found between camel milk and other mammalian milk. For example high $\beta$-casein and $\alpha$-lactalbumin content of camel milk and deficiency of $\beta$-lactoglobulin as well as low $\alpha$-casein content. These differences provide camel milk with some additional functional properties, for instance hypoallergenicity and higher digestibility in the gut of infants. These potential health claims and antidiabetic, antimicrobial, antioxidant, anticancer, and angiotension converting enzyme-inhibitory activity of camel milk are due to a number of bioactive components, which either naturally existed in camel milk or encrypted in the primary structure of its constitutes. White treasure is also considered as a rich source of vitamin $\mathrm{C}$ for people living in the desert where vegetables and fruits are not available and contains substantially higher content of $\mathrm{Na}, \mathrm{K}, \mathrm{Fe}, \mathrm{Cu}$ and $\mathrm{Mn}$ compared to cow's milk. Nowadays, camel milk has developed a high reputation
Volume 4 Issue 5 - 2016

Omar Amin Alhaj

Department of Food Science \& Nutrition, King Saud University, Saudi Arabia

Correspondence: Omar Amin Alhaj, Department of Food Science \& Nutrition, College of Food and Agricultural Sciences, King Saud University, Riyadh, I I45 I, PO. Box 2460, Saudi Arabia, Email oalhaj@ksu.edu.sa

Received: July 5, 2016 | Published: July 07, 2016

and available in the market shelves worldwide include Middle East, Europe and United States of America due to increase demand. The commercial available products include cheeses ultra-heat treated and pasteurized milk, ice cream, and chocolates.

\section{Acknowledgements}

None.

\section{Conflict of interest}

Author declares that there is no conflict of interest. 